- Revista de Iniciação à Docência, v. 2, n. 1, 2017 Publicação: dezembro, 2017 - ISSN 2525-4332

\title{
MULHER, LÍNGUA PORTUGUESA, LITERATURA E PRODUÇÃO TEXTUAL: EXPERIÊNCIAS DO ESTÁGIO SUPERVISIONADO
}

Edmila Silva de Oliveira ${ }^{1}$ Marília de Souza Sanches ${ }^{2}$

RESUMO: Este trabalho relata as atividades que foram desenvolvidas durante a disciplina de Estágio Supervisionado II do curso de Licenciatura em Letras da Universidade Estadual do Sudoeste da Bahia - UESB, Campus de Jequié. Além disso, refletiremos acerca da iniciação à docência enquanto um processo indispensável na formação do professor de Língua Portuguesa e suas literaturas. A proposta ocorreu no Colégio Polivalente Edvaldo Boaventura, na turma do $2^{\circ}$ ano $\mathrm{A}$ do Ensino Médio regular da rede pública estadual. Inicialmente foram realizados períodos de observação e coparticipação, nos quais foram feitas algumas reflexões a respeito de como se dá a dinâmica da escola e, principalmente, de como ocorre o processo de aprendizagem em sala de aula. Por fim, ocorreu o estágio de regência, ponto alto da disciplina Estágio Supervisionado II. As experiências evidenciaram que o contato inicial com o espaço educativo contribui significativamente tanto para a iniciação à docência, quanto para os processos de formação docente.

Palavras-Chave: Estágio; Regência; Docência; Aprendizagem.

\section{Iniciação à Docência: Primeiros Passos}

O Estágio Supervisionado é uma das primeiras experiências que o estudante tem com a prática docente. É neste momento que encontra a possibilidade de relacionar a teoria adquirida durante todo o curso de licenciatura com a prática na escola, num exercício contínuo de aprender a profissão, bem como numa perspectiva crítica e reflexiva do que é a docência.

Neste processo de vivências de prática de estágio, o futuro professor tem a possibilidade de se autoavaliar ao final de cada atividade, com o intuito de manter as boas práticas e repensar as que não estão em consonância com o projeto traçado por ele, com base nas teorias estudadas e de acordo com a realidade que já foi observada e registrada por ele nos processos anteriores à regência.

Segundo Barreiro e Gebran (2006),

(...) a identidade do professor é construída no decorrer do exercício da sua profissão, porém, é durante a formação inicial que serão sedimentados os

\footnotetext{
${ }^{1}$ Graduada em Pedagogia pela Universidade do Estado da Bahia - UNEB (2011); Graduada em Letras - Língua Portuguesa e suas Literaturas pela Universidade Estadual do Sudoeste da Bahia - UESB (2017). E-mail: edmilaoliveira@hotmail.com

${ }^{2}$ Graduada em Letras - Língua Portuguesa e suas Literaturas pela Universidade Estadual do Sudoeste da Bahia - UESB (2017).
} 


\section{- Revista de Iniciação à Docência, v. 2, n. 1, 2017 - Publicação: dezembro, 2017 - ISSN 2525-4332}

pressupostos e as diretrizes presentes no curso formador, decisivos na construção da identidade docente (BARREIRO; GEBRAN, 2006, p. 20).

Nesse sentindo, o estágio se configura enquanto um espaço de reflexão e formação da identidade profissional, pois coloca o estagiário diante de situações que envolvem a vivência com os docentes, discentes e toda a comunidade escolar com os alunos e isso colabora com a busca que deve ser feita de uma base para o exercício da atividade docente.

A formação profissional do aluno/estagiário é, sem dúvida, sustentada a partir do contato direto com alunos, da vivência com professores e funcionários da instituição em que realiza o estágio, pois estas etapas são verdadeiros instrumentos de conhecimento e de integração com o ambiente escolar. Vale ressaltar que a Lei 9.394/96 (Lei de Diretrizes e Bases da Educação Nacional) exige a realização do Estágio de Licenciatura e o cumprimento de sua carga horária é requisito exigido para a conclusão do curso.

Ao chegar à turma do $2^{\circ}$ Ano A do Colégio Polivalente Edvaldo Boaventura, já havíamos tido clareza e compreensão da dinâmica do estágio e da importância da nossa presença na escola, visto que, estes são quesitos primordiais para a realização de um estágio comprometido com a realidade escolar e com nossa formação docente. A turma recebeu as estagiárias com entusiasmo. Desde os momentos destinados à observação, percebemos o interesse deles com relação à "mudança de metodologia", sentiam-se desanimados, desestimulados e relataram sobre a certeza de que faríamos a diferença nas aulas da III Unidade.

No período de observação pensamos em que tipo de trabalho seria desenvolvido junto com a turma, avaliamos o que poderia ser mudado e melhorado no processo de ensino e aprendizagem, enfim, poder observar com um olhar investigativo nos dá possibilidades de realizar intervenções positivas na realidade escolar dos estudantes.

Na escola, foi possível perceber um ambiente agradável, bom relacionamento entre direção, professores, estudantes e todos os outros funcionários. A direção estava sempre disposta a atender as demandas que surgiam; os alunos iam com frequência na sala da direção fazer reclamações, dar sugestões, entre outros.

Ainda de acordo com Barreiro e Gebran (2006)

(...) a observação é relevante quando temos claro qual é o seu objeto; caso contrário, pode-se coletar informações inúteis e desconsiderar outras essenciais. o que se vai observar precisa estar de acordo com a finalidade que se tem em mente ao realizar a observação. Ou seja, o que se busca compreender? (BARREIRO; GEBRAN, 2006, p. 92)

Nesse sentido, o período de observação foi, sem dúvida, muito proveitoso para nós, pois pudemos analisar as condições e limitações da turma, a fim de traçar o perfil dela, além de ser o momento de começarmos a traçar estratégias de ensino que puderam, mais tarde, 


\title{
- Revista de Iniciação à Docência, v. 2, n. 1, 2017 - Publicação: dezembro, 2017 - ISSN 2525-4332
}

ser desenvolvidas durante a realização da regência. Este período foi propício também para trocarmos informações com a turma e com a professora regente.

Detectamos também diversas dificuldades dos estudantes, entre elas, a de compreender o assunto que estava sendo trabalhado; muita conversa na sala de aula, o que causava uma grande dispersão, para alguns frequentar as aulas ou não era a mesma coisa. Ficou claro que muitos apresentavam sérias dificuldades de aprendizagem e elas não diziam respeito somente aos conteúdos, eram problemas de base.

Para Barreiro e Gebran (2006):

\begin{abstract}
A presença do estagiário na sala de aula causa certa desestabilização nos alunos da classe diante do elemento novo (especialmente nos primeiros dias), e insegurança no professor em relação à sua própria imagem. Ele se sente pressionado no que diz respeito aos seus conhecimentos específicos e pedagógicos, a sua competência e a forma como se relaciona com seus alunos [...] a partir da percepção dele e do estagiário, que estão em campos diferentes (BARREIRO; GEBRAN, 2006, p. 98).
\end{abstract}

Foi justamente o que notamos ao chegar: os alunos com um olhar de expectativa com relação a como seria dali para frente; e a professora, por mais que tentasse demonstrar segurança, dava sinais de que a presença das estagiárias poderia, de alguma forma, significar fiscalização, observação para o destaque de críticas desfavoráveis ao seu trabalho. Apesar disso, deixou claro que o melhor deveria ser feito pela turma, tanto por ela enquanto professora regente, quanto por nós, que estávamos ali construindo nossa identidade docente.

Percebemos que é neste período de coparticipação que temos a oportunidade de nos envolver com os alunos durante as aulas, pensar em estratégias para a elaboração do projeto e realização da regência e começar a contribuir de forma significativa e responsável com a aprendizagem dos alunos. Esses momentos iniciais de observação e coparticipação com os discentes foram importantes para ratificarmos a nossa grande responsabilidade no momento do Estágio de Regência, além disso, serviram também para reafirmar o nosso compromisso com a educação e os processos educativos.

\section{Algumas reflexões sobre o ensino de Língua Portuguesa, Literatura e produção textual a partir do trabalho com a temática "mulher"}

Uma das grandes problemáticas das aulas de Língua Portuguesa do Ensino Médio oferecido nas escolas brasileiras é a divisão do ensino em Gramática, Literatura e Produção Textual. Apesar de alguns avanços nas práticas pedagógicas desenvolvidas, é importante continuar com discussões e propostas que abarquem a integração e o diálogo da língua e literatura, principalmente no curso de Licenciatura em Letras, cuja formação inicial do professor é efetivada. 


\section{- Revista de Iniciação à Docência, v. 2, n. 1, 2017 - Publicação: dezembro, 2017 - ISSN 2525-4332}

Considera-se que o texto é o ponto de partida e, ao mesmo tempo, o ponto de chegada para as articulações e interações que promovem metodologias no intuito de aproximar os estudos do campo da Literatura e da Linguística. Nesse sentido, é imprescindível que graduandos e professores conheçam e aprofundem suas percepções sobre o que é, de fato, ensinar língua e ensinar literatura a partir da própria trajetória histórica dessas disciplinas na escola.

Outras ações importantes são: conhecer, analisar, refletir e apropriar-se dos conceitos que tem orientado os princípios, objetivos, funções e o lugar desses componentes curriculares tanto na escola quanto na sociedade. Em épocas passadas, o estudo do texto literário era feito com o objetivo de explorar frases e orações isoladas como modelo de estruturas gramaticais bem elaboradas, ou, simplesmente, ler obras literárias para formar o gosto a partir de escolhas aleatórias e sem as devidas orientações didáticas, isto é, a leitura era feita sem significado/sentido, os alunos "liam por ler". É inadmissível que, ainda hoje, esse modelo seja praticado nas escolas.

De um modo geral, as atividades propostas pelo projeto que desenvolvemos no Estágio Supervisionado intitulado “Mulher: encontros, contos e encantos" foram incentivos para que os alunos despertassem o interesse pela leitura e pela produção textual, tudo isso por meio da integração entre Língua Portuguesa, Literatura e Redação, tendo como principal suporte o trabalho com os gêneros textuais.

Sabe-se que a inserção dos gêneros textuais nas aulas de Língua Portuguesa vem mudando a perspectiva do ensino de linguagem no Brasil. Professores têm se mobilizado para o trabalho com a língua em uso, por meio de gêneros textuais diversos, sempre na tentativa de adequar os textos com a realidade do estudante. Essa mudança de perspectiva não é tão simples de ser efetivada, pois a falta de conhecimento científico e de preparo dos profissionais da educação em lidar com as novas demandas relacionadas ao mundo tecnológico/digital tem feito com que o ensino tradicionalista permaneça sendo praticado.

Um dos maiores auxílios fornecidos ao professor são os Parâmetros Curriculares Nacionais (PCN), os quais apresentam propostas de trabalho que valorizam a participação crítica do aluno diante da sua língua e que mostram as variedades e pluralidade de uso inerentes a qualquer idioma. Os PCN foram elaborados pelo Governo Federal e são referências de qualidade para os ensinos fundamental e médio do Brasil. O intuito é propiciar subsídios para a elaboração e reelaboração do currículo, tendo em vista um projeto pedagógico em função da cidadania do aluno e uma escola com um nível de qualidade no ensino cada vez maior.

Segundo Marcuschi (2005, p. 22) “[...] é impossível se comunicar verbalmente a não ser por algum gênero, assim como é impossível se comunicar verbalmente ao não ser por algum texto [...]". Então, percebemos que os gêneros textuais são os diversos textos que ocorrem na sociedade, encontrados no nosso cotidiano, podendo ser orais e escritos, desde que apresentem aspectos ligados às práticas sociais. Vale ressaltar que cada gênero 


\section{- Revista de Iniciação à Docência, v. 2, n. 1, 2017 - Publicação: dezembro, 2017 - ISSN 2525-4332}

possui uma função social, sendo usados em momentos específicos de interação de acordo com essa função. Alguns exemplos de gêneros são: entrevista, carta comercial, carta pessoal, romance, notícias jornalísticas, artigo de opinião, novela, receita, fábula.

Antunes (2003) faz um convite aos professores para que seja feita uma reflexão crítica sobre determinadas práticas tradicionais no ensino de português e propõe que desenvolvam pesquisas e atividades pedagógicas dinâmicas, possibilitando a prática constante da leitura e escrita dos alunos. A discussão presente com relação à educação está direcionada para a:

(...) concepção interacionista, funcional e discursiva da língua, da qual deriva o princípio geral de que a língua só se atualiza a serviço da comunicação intersubjetiva, em situações de atuação social e através de práticas discursivas materializadas em textos orais e escritos (ANTUNES, 2003, p. 42).

O projeto aqui relatado, elaborado para o estágio, enfatizou a inserção de gêneros textuais variados na sala de aula como: relatórios, artigos de opinião, cartas, requerimentos, poemas, resumos, entrevistas, dentre outros. Acreditamos que a inclusão desses gêneros na escola, além promover a ampliação de competências no uso oral e escrito da língua pelos alunos, pode proporcionar também a aquisição do conhecimento de mundo, contribuindo para uma compreensão coerente dos textos nas diversas situações sociais.

A proposta que realizamos teve como temática geral "Mulher", dentro do contexto do Realismo/Naturalismo (processos literários trabalhados na III Unidade), além de relacionar com os conteúdos "Verbo", “Conto", “Crônica”, “Artigo de Opinião" e "Editorial". Os diversos gêneros textuais subsidiaram a proposta de trabalho que envolveu leitura e produção textual, já que os gêneros dialogam entre textos orais e escritos.

Durante as observações das aulas, notamos que havia apenas dois homens em uma turma com 22 estudantes; e um dos assuntos constantes entre eles era a violência contra mulheres, por ser recorrente nas mídias ou por simples curiosidade. Por isso consideramos interessante propor aos estudantes uma reflexão sobre a postura da mulher perante a sociedade.

Para fundamentar o debate, salientamos o século XIX, período de transição do romantismo para o realismo, para então conferir as informações com a atualidade. Tratamos não somente de fatos contra a mulher, mas também dos valores relacionados à família e ao casamento de diferentes mulheres, além do comportamento da mulher, a partir de uma análise da representação na literatura comparando sua influência na sociedade atualmente.

Por perceber que ainda hoje ainda são muito marcantes os discursos/atitudes reprodutores de hierarquias de gênero que se baseiam na dicotomia homem/masculino e mulher/feminino, consideramos pertinente trabalhar a temática da mulher. A lógica 


\section{- Revista de Iniciação à Docência, v. 2, n. 1, 2017 - Publicação: dezembro, 2017 - ISSN 2525-4332}

dicotômica tem sido sustentada no decorrer dos anos, embora exista um grande grupo que tenta, a partir de pesquisas e movimentos, desconstruir ideias machistas, caminhando na direção de construir uma sociedade de fato plural, composta por principalmente por pessoas livres.

As atividades sugeridas apontaram para a reflexão dos estudantes no que se refere a um assunto presente no cotidiano e sempre atual, e a pretensão foi contribuir com um maior conhecimento e melhor vivência de cada um deles, além de despontar a criatividade e revelar o potencial asilado naquele grupo. Por se tratar de uma turma de jovens, com idade média de 18 anos, decidimos combinar as disciplinas Literatura, Redação e Língua Portuguesa, e trabalhar com textos que permitissem discutirmos o tema e aplicar os conteúdos. Isso, sem dúvida, contribuiu para um aprofundamento nas discussões e um estudo funcional da língua.

Foi este o caminho que o nosso projeto trilhou: cada aula foi pensada no diálogo entre gramática e texto. Por isso, os textos literários foram o principal suporte para a realização do estágio, com a proposta de diversas atividades que permitiram, além da leitura e compreensão textual, a identificação e classificação dos verbos nos textos trabalhados. Nesse sentido, o principal objetivo delineado foi aos poucos sendo atingido: compreender as práticas de leituras e produção textual como oportunidades de contextualização de temáticas relacionadas ao comportamento humano e vida e sociedade. Somado a isso, os estudantes tiveram a possibilidade de conhecer as representações da mulher na sociedade desde o século XIX até os dias atuais.

No que se refere à avaliação, sabe-se que avaliar é uma ação provocativa, segundo Hoffman (1995) em que o professor desafia o "[...] o educando a refletir sobre as situações vividas, a formular e reformular hipóteses encaminhando-se a um saber enriquecido" (p. 153). Implica também analisar as várias manifestações dos alunos em situações de aprendizagem verbal ou escrita, ou seja, a avaliação deve ser um mecanismo processual e contínuo.

Ainda em consonância com as ideias de Jussara Hoffman, pensamos na avaliação mediadora enquanto:

\footnotetext{
(...) ação avaliativa como uma das mediações pela qual se encorajaria a reorganização do saber. Ação, movimento, provocação, na tentativa de reciprocidade intelectual entre os elementos da ação educativa. Professor e aluno buscando coordenar seus pontos de vista, trocando ideias, reorganizando-as. (HOFFMANN, 1991, p. 67).
}

Este paradigma se opõe ao modelo enraizado que consiste em transmitir, verificar e registrar, além disso, a pretensão é evoluir no sentido de uma ação avaliativa reflexiva e desafiadora do educador em termos de contribuir, elucidar, favorecer a troca de ideias entre e com nossos estudantes. A troca de saberes é mais relevante do que o simples "transmitir", pois o intuito é ver o saber construído a partir da compreensão dos fenômenos estudados. 


\section{- Revista de Iniciação à Docência, v. 2, n. 1, 2017 - Publicação: dezembro, 2017 - ISSN 2525-4332}

Acreditamos que se o aluno é considerado um mero receptor passivo dos conteúdos sistematizados pelos docentes, ao cometer qualquer tipo de falha, ou ao não conseguir desenvolver seus argumentos, a reprovação é muito mais provável. Contudo, no momento em que o docente insere em sua avaliação, o erro a partir de uma perspectiva dialógica e construtivista, errar torna-se algo positivo, que pode dar bons frutos no que se refere ao conhecimento produzido pelo estudante. Nesse sentido,

o diálogo deve ser entendido como algo que faz parte da própria natureza histórica dos seres humanos. É parte de nosso progresso histórico, do caminho para nos tornarmos seres humanos. (...) o diálogo é o momento em que os humanos se encontram para refletir sobre sua realidade tal como a fazem e refazem" (SHOR; FREIRE, 1986, p. 122-123).

É possível que os estudantes alcancem a superação quando refletem sobre a produção dos seus próprios conhecimentos, seja por meio do acerto ou do erro. Dentro dessa maneira de pensar as avaliações realizadas está o enriquecimento do saber, com vistas a uma ação avaliativa mediadora.

As propostas avaliativas efetivadas durante o estágio foram: correção coletiva de atividades solicitadas, revisão do próprio texto produzido pelo estudante, auto avaliação, correção de atividades individuais e análise da letra da música composta pelos estudantes. Vale ressaltar que todos os exercícios realizados foram pontuados e somados para compor a nota no final da unidade, visto que, essa era a exigência institucional. Logo após, os grupos falaram brevemente do que se tratava a música que escreveram e, em seguida, cantaram. Foi um momento bom, em que eles próprios puderam refletir acerca de sua capacidade criadora. As músicas foram muito bem pensadas, os ritmos diferentes e as letras se aproximam muito da proposta, que é abordar a questão da mulher no século XIX, tendo como suporte o Realismo, conteúdo estudado durante toda a III Unidade.

\section{Considerações Finais}

Após a realização do Estágio Supervisionado II foi possível confirmar que a prática supervisionada é mais que necessária para que os futuros professores reflitam acerca das teorias vistas durante o período de aulas na Universidade. No entanto, elas não suficientes para o exercício efetivo da docência: existe uma necessidade de os estagiários vivenciarem a prática docente em escolas de Educação Básica, para que conheçam de fato o chão da escola, o cenário que futuramente será seu campo de atuação profissional. Percebe-se também que não basta que os alunos estagiários realizem apenas práticas no estágio supervisionado, eles também necessitam de momentos de reflexão sobre os diagnósticos e as vivências experimentadas durante o período do estágio.

Vários autores discutem a respeito da importância e necessidade de práticas reflexivas durante a formação inicial dos licenciandos, entre eles Pereira e Baptista (2009), 


\section{- Revista de Iniciação à Docência, v. 2, n. 1, 2017 - Publicação: dezembro, 2017 - ISSN 2525-4332}

quando afirmam que é imprescindível a realização de uma reflexão dos dilemas encontrados na prática pedagógica em sala de aula vivenciada pelos licenciandos, visando a superação dos obstáculos encontrados, como uma forma de adquirir competências e habilidades para lidar com as diversas situações que possam surgir no decorrer da carreira. Segundo os referidos autores, a partir dessa reflexão constante, os futuros professores serão capazes de avaliar a sua própria prática, diagnosticar suas principais limitações e encontrar soluções para resolver problemas.

O período de estágio é, de fato, a oportunidade que o estagiário tem de compreender e analisar os passos que são dados na sua prática pedagógica, pois a partir de toda teoria que o curso de Letras oferece é possível realizar uma prática fundamentada. Durante o período de observação e coparticipação foi possível compreender a importância dessa vivência para experimentar, na prática, as teorias que conhecemos na universidade. É um momento de grande aprendizado e desenvolvimento, pessoal e profissional, que nos faz refletir sobre a importância da formação inicial e das práticas de estágio serem pautadas pela investigação da realidade.

Nos estágios começamos a busca por uma base sólida que permita aos estudantes (licenciandos) exercitar sua futura atividade docente, então, é evidente que a formação inicial ocupa um lugar ímpar para uma docência de qualidade, tendo como um dos pontos principais a investigação, tendo a pesquisa como um princípio fundamental, um dos caminhos para a formação docente. Nessa fase de contato com a realidade escolar, o futuro professor de Língua Portuguesa, juntamente com a instituição pública, pode, entre tantas outras atividades significativas, pensar e articular melhorias para a escola a partir das intervenções realizadas.

Então, podemos finalizar afirmando que esse processo de descobertas e aprendizagens foi de grande importância para a nossa formação acadêmica, visto que contribuiu também para nossa formação pessoal, pois nos possibilitou refletir sobre a importância do papel do professor no processo de mediação do conhecimento. Além disso, foi possível reconhecer que os estudantes são sujeitos ativos no processo da aprendizagem e sem eles nada aconteceria.

\section{Referências}

ANTUNES, I. Aula de português: encontro e interação. São Paulo: Parábola, 2003.

BARREIRO, I. M. F.; GEBRAN, R. A. Prática de ensino e estágio supervisionado na formação de professores. São Paulo: Avercamp, 2006.

BRASIL. Ministério de Educação e Cultura. LDB - Lei n. 9394/96, de 20 de dezembro de 1996. Estabelece as Diretrizes e Bases da Educação Nacional. Brasília: MEC, 1996. 
- Revista de Iniciação à Docência, v. 2, n. 1, 2017 -

Publicação: dezembro, 2017 - ISSN 2525-4332

BRASIL. Secretaria de Educação. Parâmetros Curriculares Nacionais do Ensino Médio. Secretaria de Educação. Brasília: MEC, 2000.

HOFFMANN, J. Avaliação: mito e desafio - uma perspectiva construtivista. Educação e Realidade, Porto Alegre, 1991.

HOFFMAN, J. Avaliação: mito e desafio: uma perspectiva construtivista. Porto Alegre: Mediação, 1995.

MARCUSCHI, L. A. Produção textual, análise de gêneros e compreensão. 3 ed. São Paulo: Parábola Editorial, 2008.

PEREIRA, H. M. R.; BAPTISTA, G. C. S. Uma reflexão acerca do Estágio Supervisionado na formação dos professores de Ciências Biológicas, In: ENCONTRO NACIONAL DE PESQUISA EM EDUCAÇÃO EM CIÊNCIAS, 7, 2009. Atas... Florianópolis: Abrapec, 2009.

PIMENTA, S. G. O estágio na formação de professores: unidade teoria e prática? São Paulo: Cortez, 1994.

SHOR, I.; FREIRE, P. Medo e ousadia: o cotidiano do professor. Rio de Janeiro: Paz e Terra, 1986. 